\title{
Problems Don't Care about Disciplinary Boundaries
}

\author{
Regina F. Bendix
}

\begin{abstract}
Interdisciplinary collaboration is a sensible approach for addressing complex problems. However, academic training and the resulting disciplinary habitus (and competition) often leave such collaborative skills woefully underdeveloped. This contribution outlines how ethnographic sensibilities and skills may contribute to overcoming borders between disciplinary practitioners and enhancing self-awareness within and across scientific and scholarly practice. It thus proposes ethnographic attention as interdisciplinary midwifery.
\end{abstract}

\section{KEYWORDS}

ethnography, interdisciplinarity, meta-practice, problem solving

Spring 2020 finds the world in a virus-caused deceleration of social and economic life that may last weeks, perhaps months, perhaps even longer. Global 'overheating', so convincingly studied by Thomas Hylland Eriksen and his team (2016a, 2016b), certainly contributed to what the planet is facing in the twenty-first century, including the rapid spread of Covid-19 and the pandemic measures it has brought forth. While we undergo this strange mixture of quiet and worry, familial intensity or deep aloneness, we may also borrow the term to look at the world of knowledge making. As researchers and teachers in higher education, we navigate a thicket of specialisations even within single fields that might well be seen to be characterised by overheating.

We juggle the different work practices expected by successful members of a discipline, ranging from contributions to basic science, to engagement in theoretical disputes, refinement of methodological tools, and identification of possible new areas of expertise. The result of this multitasking is evident in the huge number of journals, categorised $\mathrm{A}, \mathrm{B}, \mathrm{C}$ and 'other', and the value schemes associated with different publishers, again quite different according to discipline. Good academic citizenship necessitates that we give yet more of our time to the quality control entailed in peer reviewing, not just of potential publications, but also of grants facilitating further research. To organise this profusion of tasks - including various teaching models - science 
and scholarship have developed divergent formats to write, speak and silence, internalised during disciplinary training so as to succeed on the path into research positions.

As we acquire these skills, we become hotly proficient disciplinarians, and the fire is being stoked further by the neoliberal university and its ultracompetitive disposition. On the path to excel within a chosen field, we may discipline ourselves to grow distant from formats that voice what might be overarching concerns and also personal passions (Bendix 2008). The heat of disciplinary specialisation can also burn up or scald what flexibility inquiring minds may have for interdisciplinary engagement - and yet interdisciplinarity is not just a slogan term among research deans eager to move their university into the top ten on the national funding map. Interdisciplinary work would be - as the present pandemic shows - a means to address complex problems.

A snapshot of any deeply struck Covid-19 area will illustrate that tackling the situation requires medical and care knowledge intermeshed with virology, logistics and organisational studies, built in turn on mathematical modelling; it also requires agricultural economics fathoming food security beyond the pandemic - and the solution will be better if coupled with social psychology; communications, humour studies and rumour analysis would forge well with history unearthing long forgotten parallels in lockdowns; multi-species studies and comparative nutritional studies also belong in the mix. The list could go on.

The humanities have much to contribute at this time when legal scholars outline the safety margins of maintaining democratic rights, economists try to design what stimulus packages are needed to restart a post-pandemic work life, and epi-models fathom, mathematically, how human beings under different circumstances behave. But working together, so that resultant policy papers carry the sophistication of interdisciplinary collaboration, is still a rarity, in part because we are sweating to meet disciplinary goals, in part because many humanities scholars are not conversant in the format and language customary for the 'policy paper' (which is not the same as forecasting the impact factor of one's research), and in part because the hermeneutic ethos of humanities fields has many scholars shy away from the normative implications of policy suggestions. Alas, the problems our planet is facing are hot, literally so in the realm of the climate crisis, figuratively in many other realms. They require interdisciplinary cooperation which in turn necessitates a cooling of disciplinary excess. Anthropology's ethnographic disposition, I suggest, makes for good equipment to foster and sustain interdisciplinary problem solving. 
A number of excellent insights have been generated to show the stumbling blocks that surface in interdisciplinary research endeavours, be this from the history of science (e.g. Galison 1997), learning sciences (Lave and Wenger 1991; Wenger 1998), from the interface of science and art (Born and Barry 2010), or from empirical work in social psychology (Dai 2019; Dai and Boos 2019). Having been engaged over roughly eight years in an interdisciplinary research group on cultural property and heritage matters, I came to appreciate the ethnographic approach of my own discipline as an almost indispensable component for such an undertaking. While not 'closed cultures', disciplines are nonetheless internalised edifices that offer structures of feelings and normalise practices so as to be habitual and rarely reflected. Fieldwork methods ideally render us open with all pores to the situation we find ourselves in - including that of academic institutions and activities. In addition, reflexivity has come to be an integral part of ethnographic knowledge production, ever since Elenore Bowen (aka Laura Bohannan) wrote the first ethnography daring to make fun of her own professional and cultural habits (1964).

Both fieldwork and its reflection in writing are qualities ideally suited to build and sustain interdisciplinary projects, not just researching the topic at hand but also engaging on a meta-level by studying the social life of the research group itself, and thus seeking loose stones in the walls that hold together disciplinary identities. Becoming proficient in a discipline generates trust in others who have chosen the same field. While there is competition among a discipline's disciples, there is solidarity particularly in the face of other disciplines addressing the same problem. Extending trust to scholars with other disciplinary backgrounds - or at the very least respecting each other's suspicion - is crucial for interdisciplinary collaboration. Ethnographic attention can work towards this goal in offering reflection on what are often social, not intellectual impasses.

Our research unit assembled cultural and social anthropologists, economists and legal scholars from international to civil and economic law. The group furthermore consisted of professors acting as principal investigators, postdocs, doctoral students and student assistants. It might have been possible to forge together, with some ease, the relevant, different bodies of knowledge from these fields to prepare the foundation for addressing the problems our grant had proposed to address. But what proved challenging at times to the point of despair were the scholarly habits cultivated in fully blooming careers, 
budding among postdocs, and being acquired by the most junior members of the team.

There had been great eagerness among all the principal investigators to participate in this project, both because it seemed topically interesting and because - see above - the heat is on also at our university to participate in larger research units. Once the funds were granted and the work began, the eagerness dissipated among some of them and/or was transferred to the junior scholars hired to carry out the empirical work. I began keeping field notes of our work and interactions at the regular group meetings with their evolving patterns of 'who did not show up again', the hesitation in the room to ask for clarification about unfamiliar terms across disciplinary lines (who wants to lose face?), followed by intensive yet kind hallway chats that suddenly explicated what would have benefited the whole group. I kept track of the silences, the unanswered email queries and jarring phone calls, as well as the frictions over anything from the make of the coffee machine to the online publication of working papers without footnotes referencing ideas voiced in team discussion. As time progressed, the social life of the group appeared to be as important to work on as the research questions we pursued. It was utterly useless to chide principal investigators for making themselves sparse, and far more effective to organise get-togethers involving shared meals. Some of those who joined for those components miraculously also increased their input in joint thinking and writing about cultural property.

As our group's funding drew to a close, it became ever more obvious that ethnographic attention might be activated to intervene in such well-intentioned groups. Hot disciplinarians have generally little time, least of all to reflect on their own habitus. Yet precisely such reflection is necessary to forestall the worst clashes, and to understand that they are generally interdisciplinary and not interpersonal. Kilian Bizer, Dorothy Noyes and I built on the group experiences we had had as team members and visiting fellow respectively in the cultural property group as we drafted our slender book Sustaining Interdisciplinary Collaboration (2017). We sought to pinpoint the social dimensions that are elementary for creating work environments for interdisciplinary endeavours. In discussing and writing, we also shared a lot of laughter which - as in Bowen's aforementioned Return to Laughter (1964) - would seem to be an elementary component of tackling big, hot problems by reaching across disciplinary boundaries. We took an exit from writing for our specific fields, experimented with drawings to understand just what it was that happened in the course of an 
interdisciplinary project, and managed to learn from one another in ways that we had not when it came to cultural property.

Big or hot problems will not be solved by a return to what Leibniz called universal science; the knowledge universe has grown in complexity alongside the complexity of planetary problems. But we do need ways to make interdisciplinary cooperation work more effectively; or, to stay with the metaphor, cool down our disciplinary heat and permit reflection of knowledge-making habits so as to improve work across boundaries.

Regina F. Bendix, University of Göttingen, Germany. E-mail: rbendix@gwdg.de

\section{References}

Bendix, R. F. (2008), 'Formatfrustrationen: Geschlecht, Biographie, Wissen und Wissensproduktion', in N. Langreiter, M. Haibl, K. Löffler, E. Timm and S. Blumesberger (eds), Wissen und Geschlecht [Knowledge and gender] (Beiträge der 11. Arbeitstagung der Kommission für Frauen- und Geschlechterforschung der Deutschen Gesellschaft für Volkskunde, Wien, Februar 2007; Veröffentlichungen des Instituts für Europäische Ethnologie der Universität Wien, Bd. 31) (Vienna: Institut für Europäische Ethnologie), 91-111.

Bendix, R, F., K. Bizer and D. Noyes (2017), Sustaining Interdisciplinary Collaboration: A Guide for the Academy (Urbana: University of Illinois Press).

Born, G. and A. Barry (2010), 'Art-Science: From Public Understanding to Public Experiment', Journal of Cultural Economics 3, no. 91: 103-119.

Bowen, E. [L. Bohannan] (1964), Return to Laughter (New York: Doubleday).

Dai, L. (2019), 'Opening the Black Box: Cognitive and Interpersonal Mechanics of Knowledge Interactions in Interdisciplinary Collaborative Teams', (dissertation, Social Psychology, University of Göttingen).

Dai, L. and M. Boos (2019), 'Mapping the Right Fit for Knowledge Sharing: Practical Tips for Effective Interdisciplinary Collaborations', Nature, https://www.nature. com/articles/d41586-019-03558-5 (accessed 20 April 2020).

Eriksen, T. H. (2016a), Overheating: An Anthropology of Accelerated Change (London: Pluto Press).

Eriksen, T. H. (2016b), 'Overheating: The World since 1991', History and Anthropology 27: 469-487.

Galison, P. (1997), Image and Logic: A Material Culture of Microphysics (Chicago: University of Chicago Press).

Lave, J. and É. Wenger (1991), Situated Learning: Legitimate Peripheral Participation (Cambridge: Cambridge University Press).

Wenger, É. (1998), Communities of Practice: Learning, Meaning, and Identity (Cambridge: Cambridge University Press). 